\title{
Nonprofit disease groups earmark grants for drug repositioning
}

Prompted by the low success rates and high costs of drug development, pharmaceutical companies have increasingly turned to drug repositioning, also known as repurposing, to refurbish dwindling product pipelines-but the trend has spilled beyond industry. With an increasing academic focus on translational medicine, nonprofit research organizations are also looking to encourage new uses for old drugs, and some are earmarking money specifically for the effort.

"Certainly, this is an area that seems ripe for some further investigation," Francis Collins, director of the US National Institutes of Health (NIH) in Bethesda, Maryland, told Nature Medicine.

Although the NIH has yet to formally launch any drug repositioning-specific grant schemes, some nonprofit organizations and academic institutions already have. In late July, for example, the Michael J. Fox Foundation for Parkinson's Research (MJFF) announced the recipients of its first awards designated specifically for repositioning studies. Five of the six projects, funded for a total of \$2.4 million, will take drugs originally developed for a range of ailments, including tuberculosis, depression and diabetes, and test them in animal and cellular models of Parkinson's disease. The sixth grant will fund a human trial of a pupil-dilating eye drug called tropicamide to treat uncontrolled drooling in people with Parkinson's.

"That concept of repurposing a drug is a really powerful one," says Brian Fiske, director of research programs at the New York-based MJFF. "It really just speaks to our broader mission, which is to push treatments to the clinic and to accelerate the whole process."

Fiske says the inspiration for the recent request for applications (RFA) was an earlier project, funded through the MJFF's general grant scheme, showing that the antidiabetic drug Actos (pioglitazone), although under public scrutiny for its possible link to bladder cancer, can be neuroprotective in a primate model of Parkinson's disease. The foundation, together with the US National Institute of Neurological Disorders and Stroke, is now supporting a phase 2 human clinical trial. "Stories and examples like this really make the case for a repositioning program," Fiske says.

Also in July, the University of New Mexico (UNM) Health Sciences Center's Clinical and Translational Science Center in Albuquerqueone of 60 members of the NIH's Clinical and Translational Science Awards (CTSA) consortium-issued its own call for repurposing grant applications. Although these awards are

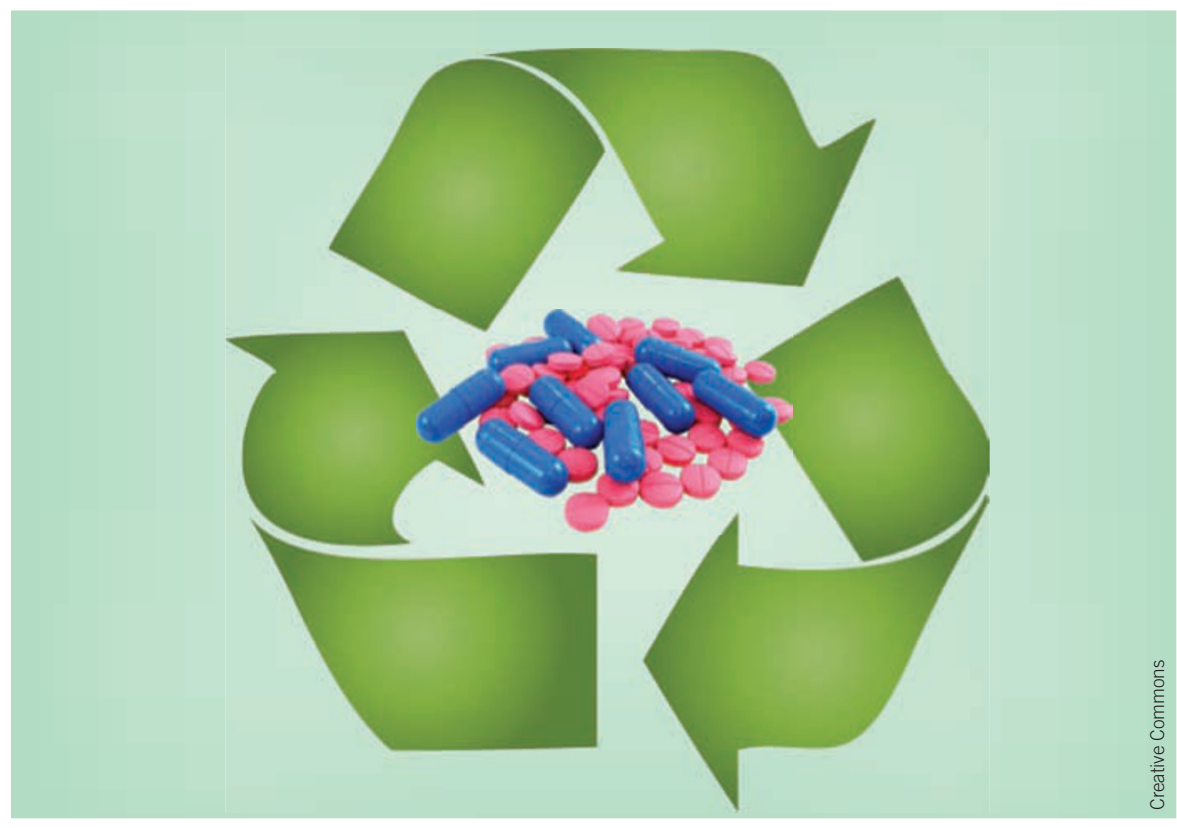

Reposition statement: Funders set money aside for drug repositioning.

small, ranging from $\$ 5,000$ to $\$ 50,000$, they are intended to help investigators secure much larger NIH grants afterward.

"This approach that we're trying to apply with the RFA allows clinical investigators to establish high-throughput screens that scan all known drugs against their molecular targets of interest," says UNM's Richard Larson, who oversees the CTSA award.

\section{Logical thinking}

Larson, who also serves as vice chancellor for research at the UNM Health Sciences Center, cites the NIH's proposed new translational medicine hub, the National Center for Advancing Translational Sciences (NCATS), as well as UNM's involvement in the federal agency's Molecular Libraries Probe Production Centers Network, as inspiration for focusing on drug repositioning. "It seemed to us, because of the impending formation of NCATS and the fact that we were in a somewhat unique position, that we would look for ways to strategically and tactically do that," he says.

It's unclear, however, whether NCATSwhich is slated to open its doors next month, pending congressional approval in the as-yet unresolved 2012 budget-will follow UNM and the MJFF's lead. "I would think of NCATS as a clearinghouse or an honest broker between companies that have compounds and investigators that have ideas about new uses," says Collins. "Does the RFA need to be there to stimulate those investigators to come up with those new uses? Maybe. But we're not far enough along, I think, to say if that's exactly the right mechanism."

To date, the agency has been taking a different approach. Two years ago, for instance, the NIH launched the CTSA Pharmaceutical Assets Portal to match researchers with drug companies sitting on shelved compounds (see Nat. Med. 16, 7, 2010). And, earlier this year, the NIH Chemical Genomics Center released a freely available database of all 8,000 or so smallmolecule drugs approved for human or animal use so that other scientists could explore them for new uses (Sci. Transl. Med. 3, 80ps16, 2011). A paper published last month describes how this resource helped identified 32 new off-theshelf drug leads for fighting malaria (Science 333, 724-729, 2011).

In April, agency officials met with representatives from industry, academia and advocacy groups for a two-day roundtable meeting to discuss ways of improving repositioning programs at the agency-and much of the focus centered around how to embed those efforts into NCATS.

"If NCATS is going to be engaged, I would see us more trying to tackle the problem systematically, as opposed to saying, 'Well, let's put out an RFA for repurposing for Alzheimer's disease or an RFA for repurposing for diabetes," says Collins. "The idea would be, instead, to try and look at all drugs, all targets, and say, 'Where's the match?"'

Elie Dolgin 